\title{
BMJ Open Disentangling the determinants of interest and willingness-to-pay for breast cancer susceptibility testing in the general population: a cross-sectional Web-based survey among women of Québec (Canada)
}

Jolyane Blouin-Bougie, ${ }^{1}$ Nabil Amara, ${ }^{1}$ Karine Bouchard, ${ }^{2}$ Jacques Simard, ${ }^{3}$ Michel Dorval ${ }^{4}$

To cite: Blouin-Bougie J, Amara N, Bouchard K, et al. Disentangling the determinants of interest and willingness-to-pay for breast cancer susceptibility testing in the general population: a cross-sectional Web-based survey among women of Québec (Canada). BMJ Open 2018;8:e016662. doi:10.1136/ bmjopen-2017-016662

- Prepublication history and additional material for this paper are available online. To view these files, please visit the journal online (http://dx.doi. org/10.1136/bmjopen-2017016662).

Received 3 March 2017 Revised 27 November 2017 Accepted 9 January 2018

D) Check for updates

For numbered affiliations see end of article.

\section{Correspondence to}

$\mathrm{PhD}$ Candidate Jolyane BlouinBougie;

jolyane.blouin-bougie@fsa. ulaval.ca

\section{ABSTRACT}

Objectives To identify common and specific individual factors that favour or impede women's interest in and willingness-to-pay (WTP) for breast cancer susceptibility testing (BCST) and to identify the most impactful factors on both outcome measures.

Design and methods This study used a self-administered cross-sectional Web-based questionnaire that included hypothetical scenarios about the availability of a new genetic test for breast cancer.

Participants French-speaking women of the general population of Québec (Canada), aged between 35 and 69 years, were identified from a Web-based panel (2410 met the selection criteria, 1160 were reached and 1031 completed the survey).

Measures The outcomes are the level of interest in and the range of WTP for BCST. Three categories of individual factors identified in the literature were used as potential explanatory factors, that is, demographic, clinical and psychosocial.

Results Descriptive statistics indicated that the vast majority of sampled women are interested in BCST (90\%). Among those, more than half of them are willing-to-pay for such a test $(57 \%)$. The regression models pointed out several factors associated with both outcomes (eg, age, income, family history, locus of control-powerful others) and marginal effects were used to highlight the most impactful factors for each outcome.

Conclusion The results of this study provide a proxy of the readiness of women of the general population to use and to pay for BCST. They also offer insights for developing inclusive and specific strategies to foster informed decision-making and guide the services offered by health organisations corresponding to women's preferences and needs.

\section{INTRODUCTION}

Personalised medicine (PM) is an important growing area of research: ${ }^{1}$ It is viewed as a significant driving economic sector ${ }^{2}$ and an

\section{Strengths and limitations of this study}

- In accordance with the economic theory, this study proposes two ordered logit regression models allowing the testing of several explanatory factors of interest in and willingness-to-pay (WTP) for breast cancer susceptibility testing (BCST).

- This study also presents insights for developing inclusive and specific strategies that could support women's informed decision-making towards BCST and the range of service offerings by health organisations with regard to this test.

- Respondents' interest and WTP are measured using a hypothetical scenario; this may have led to an overestimation of the level of interest and the sum paid out-of-pocket in a realistic situation.

- Results presented in this study should be cautiously extrapolated to other neighbouring populations as interest in and WTP for genetic testing could greatly vary between populations, tests and methods used.

encouraging avenue to improve the delivery of healthcare services, ${ }^{3-5}$ notably through patient stratification approaches. ${ }^{5-7}$ The goal of PM might be notably achieved by the use of genetic tests. They sustain two main finalities of PM: one is preventive and the other is curative. Indeed, genetic tests could be indicated for healthy patients (ie, to assess ones' susceptibility to develop a disease and to provide risk management recommendations) or be used for the benefit of patients who are ill (ie, to specify diagnosis and prognosis and to support treatment decisions). ${ }^{8}$ This distinction is essential as the decision to be genetically tested is an individual one and may depend on whether the finality of 
the genetic tests used is preventive or curative, ${ }^{9}$ that is to say that the person is healthy or ill.

Although the development of PM is seen as promising for the management of multiple diseases, breast cancer (BC) prevention remains of premier interest. ${ }^{610-12}$ It is worth noting that since the commercialisation of the BRCA1/2 mutation carrier test, many other genetic markers have been discovered. Indeed, several mutations (ie, rare genetic variations) on different genes and polymorphisms (ie, SNPs: common genetic variations present within particular subpopulations) are now known as BC susceptibility risk factors and can be detected simultaneously with recent technologies (eg, next-generation sequencing, panel-gene testing). ${ }^{13-17}$ Some genetic variants are moreover associated with greater risks than others. For instance, a mutation on BRAC1, BRCA2, TP53 or PTEN confers a high risk, as a mutation on CHECK2, PALB2 or ATM confers a moderate risk of developing BC. ${ }^{13} 1416$ In this paper, we refer to carrier or predictive genetic tests, that lead to the identification of genetic variants that substantially increase $\mathrm{BC}$ risk, as breast cancer susceptibility tests (BCST). Besides the identification of at-risk women, BCST aim to provide suitable risk-management recommendations adapted to women's BC risk level and preferences (eg, type and interval of screening-mammograms or MRI-or consideration of prophylactic interventions-mastectomy or chemoprevention). ${ }^{81819}$

Given the increasing $\mathrm{BC}$ genetic knowledge base, stratifying healthy women's BC risk is viewed as an opportunity to adapt screening programmes to maximise benefits and minimise drawbacks for the general population and the healthcare systems in a foreseeable future. ${ }^{671011152021}$ More research is however needed regarding variants that should be included in BCST targeting women of the general population. ${ }^{6}{ }^{16}$ In addition, scepticism exists for "whether publicly funded screening poses an acceptable burden on healthcare budgets'. ${ }^{22}$

Up to now, however, these tests are generally offered to women by healthcare providers working in specialised clinical settings (eg, genetic clinics or hereditary cancer programmes), but are restricted to some particular group of patients. ${ }^{62023}$ Otherwise, women may access some BCST via private companies and laboratories. ${ }^{24}{ }^{25}$ Direct-to-consumer (DTC) genetic testing is however subject to arguments and contentions by researchers, professional societies and government agencies. Their preoccupations notably concerned the overriding healthcare professionals' support (ie, counselling services), ${ }^{19} 2526$ the consumer's understanding of the test results and their implications (eg, worries, risk of discrimination, repercussions on family members), ${ }^{82627}$ the tests' validity, the appropriateness of genetic markers assessed and the reliability of risk estimates, for which no evidence-based recommendations may have been yet established. ${ }^{1625}$
In that context, it might be important to get the pulse of the end-users, and this is the focus of this paper: it aims to gain insight into the readiness of women of the general population of Québec (Canada) to integrate and use genetic information for $\mathrm{BC}$ prevention. Before going further, we present an overview of $\mathrm{BC}$ prevention services and the use of BCST in Canada.

\section{BC prevention in the Canadian context}

Canada faces similar genetic services delivery challenges as other developed countries. One important particularity is the healthcare services' organisation scheme: services are provided and managed at a provincial level, but protection and well-being are overseen by the federation. ${ }^{28}$ The extent of the funding of health services, including genetic testing or BC prevention risk-management strategies, covered by the provincial healthcare systems, thus falls under some federal regulations. ${ }^{28}$ This may result in some discrepancies in the scope of services provided across provinces. For instance, The Québec Breast Screening Program invites all women aged between 50 and 69 years to have a mammogram every 2 years. ${ }^{29}$ While other Canadian provinces offer similar free services, the age-range of the targeted women by screening programmes may slightly vary from province to province. In addition, while there is no risk stratification approach implemented in Canada, two Canadian provinces (Ontario and British Colombia) recently added some public healthcare facilities for high-risk women (ie, have a known mutation on BRAC 1 or 2 , a strong family history or had prior chest radiation).

$\mathrm{BC}$ genetic services were available in genetic clinics shortly after the discovery of BRAC1 and BRAC2 in the mid-1990s in Canada. ${ }^{23}$ It confers a well-established experience in managing the genetic risk of $\mathrm{BC} .{ }^{15}$ However, only a small proportion of women currently have access to BCST, given the requirements to meet for service qualification, the complexity of the service trajectory $^{6}$ and the limited number of healthcare providers authorised to order a genetic test. ${ }^{18}$ BCST are only offered to some patients with newly diagnosed BC and their relatives and to those with a strong BC family history. ${ }^{23}$ The cost of these tests is covered for those who meet the criteria and have been referred by their provider to a genetic clinic for counselling. Women may thus have to go through a long and complex process, which often implies meeting various providers before testing and choosing a risk-management strategy that best fits their preferences and needs. ${ }^{6} 18$

Furthermore, Canadian healthcare systems are known to be publicly funded, but there are private healthcare delivery channels (eg, private clinics, laboratories and companies, complementary private insurance market), and the health sector is facing continuous pressures for service privatisation. ${ }^{30}$ Some BCST are also directly available from private companies, given the greater number of firms offering these tests to consumers. Even though the majority of those 
societies are located in USA, their geographic situation is of minor importance: genetic tests can be bought via the Web. ${ }^{31}$

\section{LITERATURE BACKGROUND}

Notwithstanding the issues discussed above, previous studies have shown that women might demonstrate interest in and willingness-to-pay (WTP) for genetic testing as results may reduce uncertainty, offer some reassurance, guide life or family planning decisions and may be useful to other family members. ${ }^{9} 242732-34$ The literature also underlined a great variability regarding populations (patients, general population, family members and so on) and health conditions when measuring levels of interest ${ }^{9}$ and estimating WTP values. ${ }^{32}$ This point supports the relevance of conducting a study for BCST in the particular context of Québec. Moreover, while the literature shows the existence of an association between interest in and cost of genetic tests for cancer susceptibility, ${ }^{27}$ 35-38 there is no consensus on which one influences the other. Consistent with the economic theory, ${ }^{35} 39$ which supposes that a person's decision is a sequential process "where the decision of whether or not to consume a particular commodity is followed by the choice of how much to consume», ${ }^{39}$ we propose two regression models assessing (1) interest in BCST and (2) WTP for this type of tests among those interested. In addition, many studies attempting to assess interest in genetic testing identify predictors in an ad hoc manner without grounding them in theory, which leads to inconsistent findings. ${ }^{9}$ While the literature on WTP constitutes another stream of research, previous studies appeared to use numerous similar predictors. ${ }^{92}$ To deal with these issues, we identified a list of recurrent individual variables empirically tested in the context of cancer susceptibility testing. Inspired by the classifications of Sweeny et at and Lin et $a l^{32}$ these variables were thereafter classified into three categories: demographic, medical and psychosocial (see online supplementary appendix 1 for the literature overview). Finally, previous study findings did not allow a detailed understanding of how preferences and WTP values vary according to individual factors. ${ }^{32}$ We then computed the marginal effects of individual factors associated with interest in and WTP for BCST. They are an informative means for summarising how change in a response is related to change in a covariate. ${ }^{40}{ }^{41}$ This could be useful in targeting the most influential factors when designing interventions.

In light of the foregoing, the following section provides information on the method used to disentangle individual factors that influence interest in and WTP for BCST and to identify the most impactful factors on both outcomes from a sample of women living in Québec (Canada).
METHODS

\section{Sample}

The target population was made up of French-speaking women of the general population aged between 35 and 69 years, living in the province of Québec in Canada. The sample was selected from an internet panel maintained by a survey firm and weighted for age, regions and education level according to Statistics Canada census profiles. ${ }^{42}$ The sample size was calculated prior to data collection with a margin of error of $3 \%$ at a $95 \%$ CI.

\section{Data collection}

A cross-sectional Web-based survey developed from a literature review on genetic risk communication was used for this study. Respondents were asked to focus on their: general health state, BC clinical history and risk factors, level of literacy and numeracy, interest in and opinions regarding the use of BCST, reactions towards various life events, general psychological health state and demographic characteristics. The questionnaire was validated by experts in familial $\mathrm{BC}$ and pretested by the survey firm with 20 eligible women in February 2012. Their comments were collected in-person or by telephone; minor changes were made to the questionnaire to improve understanding. The questionnaire was afterward adapted for a Web platform and a survey link was sent by the firm to a sample of 2410 eligible women in March 2012. Three prize draws were offered to the participants: one of $\$ 3000$ and two of $\$ 1000$.

\section{Measures}

In order to avoid respondents' confusion, women were first advised as follows (freely translated from French) before presenting to them the items on interest and WTP: 'The next questions aim to better understand your interest in genetic tests used to assess the risk of developing a disease. The following scenarios are fictive. We will ask you how much you will be willing to pay for a genetic test. This question is only useful for the purpose of this research and does not mean that fees would be necessarily charged to get access to this test. Indeed, genetic tests requiring a simple blood testing are generally freely provided in Canada'. A hypothetical scenario was then presented to women indicating that a new genetic test, now available on the market, could be used to assess their BC risk and to adapt their screening modalities should their risk level be higher than that of the general population. No specifications on the modalities under which this test could be offered or on the genes being assessed by this test were provided to the participants. Following that, respondents were asked to rank their level of interest in receiving this test on a 5-point Likert scale ('Not at all' to 'Extremely interested'). Those having indicated to be at least 'Somewhat interested' in BCST were thereafter asked how much they would be willing to pay for this test on an 6-point ordinal scale ('Do not want to pay' to 'Would pay more than $\$ 1000$ '). All respondents who had indicated to be "Not interested at all'were not asked to answer the WTP item. Detailed information regarding the scenario, operational measures of 
outcomes and explanatory factors, including coding and main references, is presented in online supplementary appendix 2.

All clinical information needed to estimate the BC lifetime risk of the respondents, according to the Gail Model parameters, ${ }^{43}$ was collected for descriptive purposes. Some potential explanatory variables underlined in the literature were not included in the analysis for methodological concerns such as distribution of respondents or theoretical redundancy. However, no variables were removed from the models on the basis of low statistical significance because they were assumed to be of theoretical interest and expected to have some effect on women's interest in and WTP for BCST. Chosen measures were assessed with validated scales or in accordance with the scientific literature. The constructs with multiple-item scales (ie, loci of control, monitoring and anxiety) were evaluated with a principal components factor analysis; the unidimensionality criterion was satisfied. Cronbach's alpha $(\alpha)$ showed that items forming each of them were reliable. Finally, reported tolerance statistic values were all higher than 0.2 (online supplementary appendix 2); there were no multicollinearity concerns. ${ }^{44}$

\section{Statistical analysis}

A posthoc power analysis was first conducted with $G^{*}$ Power 3.1.9 to ensure that we had an appropriate number of valid cases for statistical analyses to be performed and to detect a true effect when it exists. ${ }^{45}{ }^{46}$ Second, descriptive and bivariate analyses were carried out to detail the characteristics of the sample and to assess statistical associations between outcome measures and individual factors believed to have an impact on interest and WTP for BCST (data not shown). Third, two ordered logit regression models ${ }^{47-49}$ were estimated accordingly to the assumption adopted in this study. ${ }^{\mathrm{i} 50} 51$ They were used to investigate (1) women's interest in a BCST that may lead to more frequent screening should their risk level be higher than that of the general population with the original scale and then, for those at least 'Somewhat interested', (2) women's level of WTP for this genetic test with a measure capturing three levels of WTP $(1=\$ 0,2=1$ to $\$ 100,3=\$ 101$ and over). Therefore, women who responded, in the first model, 'Not at all interested' in BCST were not included in the second analysis, that is, the model on WTP.

The ordered logit model uses an intermediate continuous variable $\mathrm{Y}^{*}$ (qualifications made by women regarding the dependent variable: INTER or WTP) in a

\footnotetext{
${ }^{\mathrm{i}}$ The two models were estimated separately even though our approach might remind the Heckman's two-step sample selection procedure. This is mainly because the types of the dependent variables of our two models do not allow an appropriate use of Heckman's procedure. Indeed, 'the Heckman two-step estimator is specifically a probit model followed by a linear regression, and there is no simple analogue for the Heckman method for discrete choice models despite the logical appeal of the process'. Moreover, the use of models other than OLS in the second stage of Heckman's two-stage method is a frequent error in studies using this method.
}

latent regression with a set of independent variables $x_{i}$. The range of the unobserved Y related to INTER and WTP was subdivided, respectively, in five and three adjacent intervals representing the classes of an observed variable, Z. Thus, it assumes a continuous process relating an unknown variable $Y$ to independent variables $x_{i}$. For each dependent variable (INTER and WTP), the outcome of respondent $i$ is represented by the latent index:

$$
\mathrm{Y}_{\mathrm{i}}^{*}=\beta_{\mathrm{i}} \mathrm{X}_{1 \mathrm{i}}+\ldots . .+\beta_{\mathrm{k}} \mathrm{X}_{\mathrm{ki}}+\varepsilon_{\mathrm{i}}=\beta \mathrm{X}+\varepsilon
$$

where:

$\mathrm{Y}_{\mathrm{i}}^{*}=$ the value of the index to the observation $i$

$x=$ a vector of independent variables

$\beta=$ the vector of parameters to be estimated

$\varepsilon=$ the error term

Equation (1) cannot be estimated because $\mathrm{Y}^{*}$ is unobserved (latent index). However, we do observe the decision made by the respondents (the five and the three outcomes discussed above) as well as the $x$-vector. Thus, in order to estimate the models, the following assumptions are made:

$$
\begin{aligned}
& \mathrm{Z}_{\mathrm{i}}=1 \text { (Outcome 1) if } \mathrm{Y}^{*}<\alpha_{1} \\
& \mathrm{Z}_{\mathrm{i}}=2 \text { (Outcome 2) if } \alpha_{1} \leq \mathrm{Y}^{*}<\alpha_{2} \\
& \ldots \\
& \mathrm{Z}_{\mathrm{i}}=\mathrm{n} \text { (Outcome n) if } \mathrm{Y}^{*} \geq \alpha_{\mathrm{n}-1}
\end{aligned}
$$

The ordering requires the thresholds $\left(\alpha_{1}, \alpha_{2} \ldots \alpha_{n-1}\right)$ to satisfy $\alpha_{1}<\alpha_{2} \ldots<\alpha_{n-1.1}$ Parameters $\beta$ and the thresholds $\left(\alpha_{1}, \alpha_{2 \ldots} \alpha_{n-1}\right)$ are simultaneously estimated using the maximum likelihood method, which maximises the probability of correct classifications. An application and a more detailed statistical description of the ordered logit models are presented by Amara et $a l^{52}$ All those analyses were performed with SPSS V.13.0. ${ }^{53}$ Finally, in order to assess the magnitude of the impact of explanatory variables on interest in and WTP for BCST, the marginal effects of the significant independent variables were ascertained with LIMDEP V.8.0 Econometrics Software Package. ${ }^{54}$

\section{RESULTS \\ Descriptive statistics}

Overall, 1160 women were reached with the data collection procedure used. Among them, 40 clicked the questionnaire's link after the data collection period, 81 did not complete the questionnaire and 8 cancelled their panel subscription. The survey generated 1031 usable questionnaires for a net response rate of $43 \%$ (ie, when we consider all women who were not reached among eligible participants).

The sample was mostly composed of white educated women, in a civil union, and living in a large urban area (>100000 inhabitants) (table 1). Moreover, most of the respondents overestimated both their personal BC lifetime risk (mean $=33.05 \% ; \mathrm{SD}=22.25 \%$ ) and that of women in the general population (figure 1). However, according to the Gail Model parameters, ${ }^{43}$ approximately $85 \%$ of the respondents had less than a $15 \%$ life-time risk of BC. 
Table 1 Demographic characteristics of the sample*

\section{Age}

\begin{tabular}{|c|c|}
\hline \multicolumn{2}{|l|}{ Age } \\
\hline $35-49$ years & $503(48.8)$ \\
\hline $50-69$ years & $528(51.2)$ \\
\hline Sys miss & 0 \\
\hline \multicolumn{2}{|l|}{ Ethnicity } \\
\hline White & $977(94.8)$ \\
\hline Other & $54(5.2)$ \\
\hline Sys miss & 0 \\
\hline \multicolumn{2}{|l|}{ Marital status } \\
\hline Widowed, divorced or separated & $186(18.1)$ \\
\hline Single & $152(14.7)$ \\
\hline Married or common-law & $689(66.9)$ \\
\hline Sys miss & $4(0.4)$ \\
\hline \multicolumn{2}{|l|}{ Education } \\
\hline No diploma or secondary school & $399(38.7)$ \\
\hline College or CEGEP diploma & $265(35.6)$ \\
\hline University degree & $367(35.6)$ \\
\hline Sys miss & 0 \\
\hline \multicolumn{2}{|l|}{ Employment } \\
\hline Full time & $573(55.6)$ \\
\hline Part time & $138(13.4)$ \\
\hline Retired & $180(17.5)$ \\
\hline Student & $15(1.5)$ \\
\hline Unemployed/not working & $111(10.8)$ \\
\hline Sys miss & $14(1.4)$ \\
\hline
\end{tabular}

Household size

\begin{tabular}{|cc}
\hline 1 & $135(13.1)$ \\
\hline 2 & $403(39.1)$ \\
3 & $192(18.6)$ \\
4 & $181(17.6)$ \\
\hline $5+$ & $102(9.9)$ \\
\hline Sys miss & $18(1.7)$ \\
\hline Location area & $146(142.0)$ \\
\hline Rural & $138(13.4)$ \\
\hline Small urban & $95(9.2)$ \\
\hline Medium urban & $636(61.7)$ \\
\hline Large urban & $16(1.6)$ \\
\hline Sys miss & $878(85.2)$ \\
\hline Objective risk of BC $\dagger$ & $122(11.8)$ \\
\hline$<15 \%$ & $31(3.0)$ \\
\hline$>15 \%$ & \\
\hline Sys miss & $229(22.2)$ \\
\hline Perceived personal risk & $555(53.8)$ \\
\hline$<15 \%$ & \\
\hline$>15 \%$ & \\
\hline
\end{tabular}

Continued
Table 1 Continued

\begin{tabular}{lc}
\hline Respondents' characteristics & $\mathbf{n}=1031(\%)$ \\
\hline Sys miss & $247(24.0)$ \\
\hline Family history & \\
\hline One or more first degree relative & $146(14.2)$ \\
No family history & $869(84.4)$ \\
\hline Sys miss & $16(1.6)$ \\
\hline Interest & \\
\hline Not interested & $93(9.0)$ \\
\hline Somewhat interested & $113(11.0)$ \\
\hline Moderately interested & $221(21.4)$ \\
\hline Very interested & $389(37.7)$ \\
\hline Extremely interested & $200(19.4)$ \\
\hline Sys miss & $15(1.5)$ \\
\hline WTP & \\
\hline Do not want to pay & $250(24.2)$ \\
Between $\$ 1$ and $\$ 100$ & $362(35.1)$ \\
\hline Between $\$ 101$ and $\$ 250$ & $153(14.8)$ \\
Between $\$ 251$ and $\$ 500$ & $59(5.7)$ \\
Between $\$ 501$ and $\$ 1000$ & $13(1.3)$ \\
\hline Over $\$ 1000$ & $3(0.3)$ \\
Sys miss & $191(18.5)$ \\
\hline
\end{tabular}

*Sys miss category is the sum of the system missing data, and the option of answers 'do not know' and 'do not want to answer'. †Calculated with the Gail model parameters (available online: http://www.cancer.gov/bcrisktool/). Absolute BC lifetime risk of a woman of the general population is of $11 \%-12 \%$. However, risk prediction models used pure cumulative risk (ie, when no competing mortality risk exists), which is often higher than the absolute risk. ${ }^{80}$

$\mathrm{BC}$, breast cancer.

Descriptive statistics also revealed that $89 \%$ of the respondents were interested in BCST that may lead to more frequent screening, and $57 \%$ were willing to pay a certain amount of money to get the test. Furthermore, the one-way analysis of variance performed on ranked data indicates that there is at least one mean rank difference between ranges of WTP $(F(2,837)=83$ 992; $\mathrm{P}<0.000)$. The Tamhane's posthoc analysis, used when homogeneity of variances are not assumed (Levenes' test: $F(2,837)=6802$; $\mathrm{P}=0.001$ ), shows that the mean rank of interest in BCST significantly varies across the three ranges of WTP values (table 2): the more women are interested in BCST, the larger is the amount they are willing to pay for this tests.

\section{Common explanatory factors of interest and WTP}

The results of the estimation of the two ordered logit models are presented in table 3 . For both models, the results suggest that having a BC family history rather than none, having a locus of control highly attributed to powerful others, being widowed, separated or divorced rather than being married or in a union and having a perception of health status as good instead of excellent 


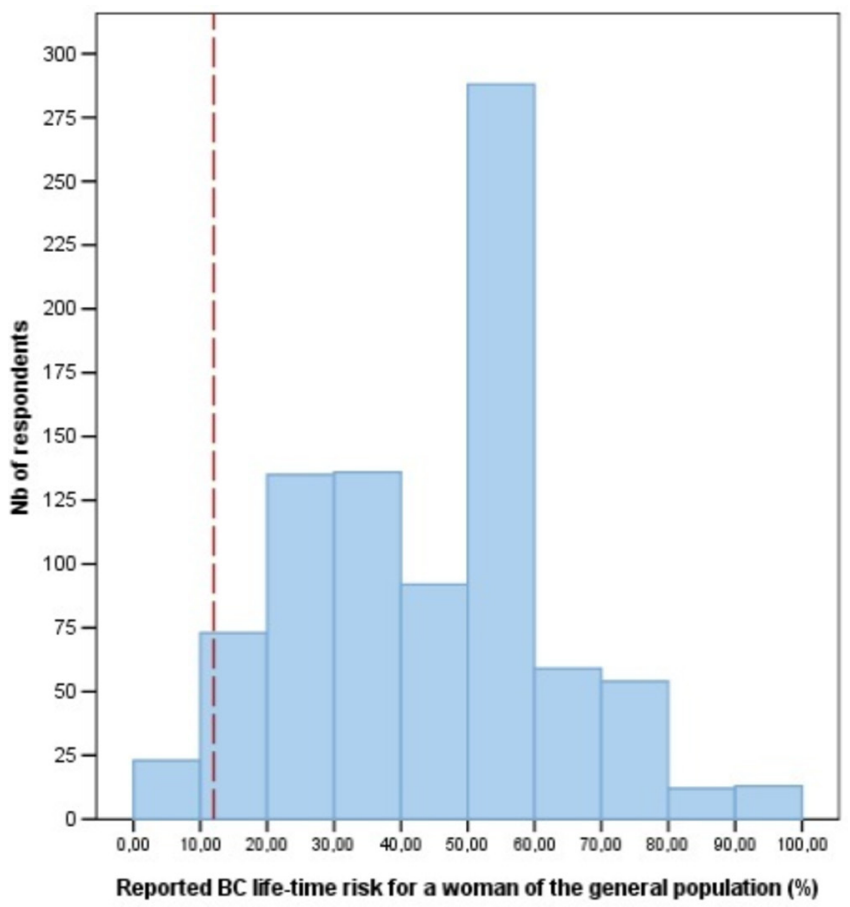

Figure 1 Respondents' distribution of reported BC life-time risk for a woman of the general population. Bar: Mean $=41 \%$, $\mathrm{SD}=18.6 \%, \mathrm{Nb}$ of case $=885$, Sys miss $=146$. Vertical dashed line: $\mathrm{BC}$ life-time risk of a woman in the general population is of $11 \%-12 \%$ (correct answer). BC, breast cancer.

or very good, are all significantly associated with a higher interest in and higher WTP for BCST.

Conversely, having a high numeracy score compared with a low numeracy score, a household income of less than $\$ 55000$ comparatively to a household income of $\$ 75000$ and over and being aged under 50 rather than being aged 50 and over, are all significantly associated with a lower interest in and lower WTP for BCST. The variables biopsy, parity and education appeared to have no impact on either interest in or WTP for BCST.

Regarding marginal effects, the coefficients show that BC family history, household income and locus of control-powerful others are the common explanatory variables that have the highest impact on women's interest in and WTP for BCST.

\section{Specific factors associated with interest in BCST}

Furthermore, there were several explanatory variables that were significantly associated only with interest in BCST. Indeed, being a high monitor compared with a low monitor and having a higher perceived risk of $\mathrm{BC}$ are significantly associated with a higher interest, while being highly optimistic rather than being poorly optimistic and having a locus of control highly attributed to chance are significantly associated with a lower interest for BCST.

More specifically, locus of control-powerful others, level of anxiety and BC family history stand with the highest marginal impact values, respectively of 0.441 , 0.409 and 0.357 . For the two former continuous variables, this implies that a positive relative change of $10 \%$ on these factors increases the level of women's interest in BCST by $4.41 \%$ and $4.09 \%$. For the categorical variable, it means that interest in BCST is $35.7 \%$ greater among women with a family history of BC comparatively to those without.

\section{Most impactful factors on WTP for BCST}

For the WTP model, variables with the highest marginal effects are locus of control-powerful others (marginal effect $=0.283$ ), BC family history (marginal effect $=0.208$ ) and household income (marginal effect $=-0.154,-0.103$ and -0.079 ). These coefficients indicate that for a positive relative change of $10 \%$ on the locus of control-powerful others score, women's WTP for BCST would increase by $2.83 \%$. This also means that WTP for BCST is $20.8 \%$ greater among women with a family history compared with those without and is as much as $15.4 \%$ lower among women with a household income of less than $\$ 75000$ compared with those with an income of $\$ 75000$ and over.

Table 2 Multiple mean group comparisons and posthoc analysis: level of interest according to range of WTP

\begin{tabular}{lcccccc}
\hline $\begin{array}{l}\text { Level of interest in } \\
\text { BCST by range of } \\
\text { WTP values* }\end{array}$ & $\begin{array}{l}\text { Somewhat } \\
\text { interested }\end{array}$ & $\begin{array}{l}\text { Moderately } \\
\text { interested }\end{array}$ & $\begin{array}{l}\text { Very } \\
\text { interested }\end{array}$ & $\begin{array}{l}\text { Extremely } \\
\text { interested }\end{array}$ & Total & $\begin{array}{l}\text { Subsets of level of WTPt according to } \\
\text { interest in BCST (mean rank) }\end{array}$ \\
\hline $\begin{array}{l}\text { Do not want to pay } \\
\text { Between }\end{array}$ & 68 & 84 & 72 & 26 & 250 & 421.76 \\
$\begin{array}{l}\text { \$0 and \$100 } \\
\text { More than } \$ 101\end{array}$ & 53 & 88 & 182 & 59 & 362 & 552.83 \\
Total & 106 & 27 & 103 & 93 & 228 & \\
\hline
\end{tabular}

*All missing data, including options 'Do not want to answer' or 'Do not know', were coded as missing system data ('sys miss'). The 191 missing data on the WTP measure are distributed as follows: 15 missing system data on the Interest measures, 93 respondents 'Not at all interested' in BCST and 83 respondents having indicated to be at least 'Somewhat interested' in BCST, but having indicated 'Do not want to answer' or 'Do not know' on the WTP measure.

†Multiple means comparisons based on Tamhane's test: the posthoc analysis was performed following an one-way ANOVA on ranked data. The numbers in columns representing the subsets of level of WTP are mean rank of interest. All mean differences are significant at $P<0.000$. ANOVA, analysis of variance; BCST, breast cancer susceptibility testing; WTP, willingness-to-pay. 
Table 3 Estimated ordered logit models of factors affecting women's interest and WTP for BCST allowing more frequent screenings

\begin{tabular}{|c|c|c|c|c|}
\hline \multirow[b]{3}{*}{ Explanatory factors } & \multicolumn{2}{|l|}{ Step 1} & \multicolumn{2}{|l|}{ Step 2} \\
\hline & \multicolumn{2}{|c|}{$\begin{array}{l}\text { Outcome } \\
\text { interest (INTER) } \\
(1=\text { Not interested at all to } 5=\text { Extremely } \\
\text { interested) }\end{array}$} & \multicolumn{2}{|c|}{$\begin{array}{l}\text { Outcome } \\
\text { Willingness-to-pay (WTP) } \\
\text { (1=\$0;2=\$1 to } \$ 100 ; 3=1 \$ 01 \text { and more) }\end{array}$} \\
\hline & Coefficients $(\beta)$ & Marginal effect† & Coefficients ( $\beta$ ) & Marginal effect $†$ \\
\hline \multicolumn{5}{|l|}{ Sociodemographic factors } \\
\hline Age (AGE) & $-0.215^{\star}$ & -0.054 & $-0.555^{\star \star \star}$ & -0.058 \\
\hline \multicolumn{5}{|l|}{ Household income } \\
\hline Less than $\$ 25,000$ (INC1) & $-0.667^{\star \star \star}$ & -0.101 & $-2.081^{\star \star \star}$ & -0.154 \\
\hline$\$ 25,000$ to $\$ 54,999$ (INC2) & $-0.510^{\star * \star}$ & -0.098 & $-1.083^{\star \star *}$ & -0.103 \\
\hline$\$ 55,000$ to $\$ 74,999$ (INC3) & -0.074 & - & $-0.762^{\star \star \star}$ & -0.079 \\
\hline$\$ 75,000$ and over (INC4) & Benchmark & & Benchmark & \\
\hline \multicolumn{5}{|l|}{ Marital status } \\
\hline $\begin{array}{l}\text { Widowed-Separated-Divorced } \\
\text { (WSD) }\end{array}$ & $0.284^{*}$ & 0.027 & $0.381^{*}$ & 0.038 \\
\hline Single (SING) & 0.184 & - & 0.201 & - \\
\hline Married or in union [MARUN] & Benchmark & & Benchmark & \\
\hline \multicolumn{5}{|l|}{ Education } \\
\hline $\begin{array}{l}\text { No diploma or secondary school } \\
\text { diploma (EDUC1) }\end{array}$ & -0.074 & - & -0.168 & - \\
\hline $\begin{array}{l}\text { College or CEGEP diploma } \\
\text { (EDUC2) }\end{array}$ & -0.218 & - & -0.004 & - \\
\hline $\begin{array}{l}\text { University diploma or degree } \\
\text { (EDUC3) }\end{array}$ & Benchmark & & Benchmark & \\
\hline \multicolumn{5}{|l|}{ Medical factors } \\
\hline Biopsy (BIOPSY) & -0.213 & - & -0.358 & - \\
\hline Parity (PARITY) & 0.060 & - & 0.131 & - \\
\hline Familial history (FAMHIS) & $0.319^{* \star}$ & 0.357 & $0.396^{\star *}$ & 0.208 \\
\hline \multicolumn{5}{|l|}{ Psychological factors } \\
\hline Optimism (OPTIMS) & $-0.299^{*}$ & -0.045 & 0.122 & - \\
\hline Monitoring (MO_MBSS) & $0.464^{\star \star \star}$ & 0.054 & 0.115 & - \\
\hline \multicolumn{5}{|l|}{ Health locus of control } \\
\hline Powerful others (PHLC) & $0.266^{\star \star \star}$ & 0.441 & $0.211^{\star \star \star}$ & 0.283 \\
\hline Internal (IHLC) & -0.040 & - & -0.103 & - \\
\hline Chance (CHLC) & $-0.190^{\star \star \star}$ & -0.244 & -0.050 & - \\
\hline Anxiety (ANX_K6) & $0.332^{\star \star *}$ & 0.409 & 0.213 & - \\
\hline Numeracy (NUM) & $-0.421^{\star \star \star}$ & -0.055 & $-0.304^{\star}$ & -0.094 \\
\hline Perceived risk of $\mathrm{BC}$ (RISK) & $0.070^{\star \star *}$ & 0.092 & -0.002 & - \\
\hline \multicolumn{5}{|l|}{ Perceived health status } \\
\hline Good (GOOD) & $0.285^{\star \star}$ & 0.047 & $0.513^{\star \star \star}$ & 0.035 \\
\hline Fair-Bad (FAIRBAD) & 0.428 & - & 0.378 & - \\
\hline Excellent -Very good [EXVER] & Benchmark & & Benchmark & \\
\hline \multicolumn{5}{|l|}{ Measures of goodness of fitł } \\
\hline \multicolumn{5}{|l|}{ Ancillary parameters } \\
\hline Threshold 1 & -1.434 & & -2.346 & \\
\hline Threshold 2 & -0.248 & & -0.153 & \\
\hline
\end{tabular}


Table 3 Continued

\begin{tabular}{|c|c|c|c|c|}
\hline \multirow[b]{3}{*}{ Explanatory factors } & \multirow{2}{*}{\multicolumn{2}{|c|}{$\begin{array}{l}\text { Step } 1 \\
\text { Outcome } \\
\text { interest (INTER) } \\
\text { (1=Not interested at all to 5=Extremely } \\
\text { interested) }\end{array}$}} & \multirow{2}{*}{\multicolumn{2}{|c|}{$\begin{array}{l}\text { Step } 2 \\
\text { Outcome } \\
\text { Willingness-to-pay (WTP) } \\
\text { (1=\$0; } 2=\$ 1 \text { to } \$ 100 ; 3=1 \$ 01 \text { and more) }\end{array}$}} \\
\hline & & & & \\
\hline & Coefficients $(\beta)$ & Marginal effect $†$ & Coefficients ( $\beta$ ) & Marginal effect† \\
\hline Threshold 3 & \multicolumn{4}{|l|}{0.962} \\
\hline Number of cases & \multicolumn{2}{|l|}{635} & \multicolumn{2}{|l|}{544} \\
\hline Likelihood ratio $(d f=21)$ & \multicolumn{2}{|l|}{65.861} & \multicolumn{2}{|l|}{60.961} \\
\hline Nagelkerke $\mathrm{R}^{2}$ (Pseudo $\mathrm{R}^{2}$ ) & \multicolumn{2}{|l|}{0.104} & \multicolumn{2}{|l|}{0.120} \\
\hline Percentage of correct predictions & \multicolumn{2}{|l|}{$50.23 \%$} & \multicolumn{2}{|l|}{$53.31 \%$} \\
\hline
\end{tabular}

${ }^{*},{ }^{* *}$ and ${ }^{* * *}$ indicate that variable is significant at $10 \%, 5 \%$ and $1 \%$, respectively. Given the nature of the variables assessed and the mixed findings reported for almost all of them in the literature on cancer susceptibility testing, and the number of valid cases included in the analysis, we used three commonly used alpha thresholds to provide to readers more precisions on the significance of our results. ${ }^{81-83}$ †For continuous variables, values of marginal effect represent the variation in percentage on the outcome for $1 \%$ positive relative change in the corresponding explanatory factor, while for categorical variables, marginal effect values indicate the variation in percentage on the outcome if the sub sample of respondents would share the same characteristic of those of the reference category.

¥The computation of the measures of goodness of fit of the two models leads to the conclusion that they were well behaved. This is indicated by the thresholds in increasing order $(\alpha 1<\alpha 2<\alpha 3)$ and the $\chi^{2}$ statistics that were much larger than the critical value $(P<0.000)$ in both models. The 'predictive power' of the models and the Nagelkerke $R^{2}$ values also appeared to be acceptable for such qualitative models.

BCST, breast cancer susceptibility testing; WTP, willingness-to-pay.

\section{DISCUSSION}

This study provides evidence on the common and specific individual factors associated with interest in and WTP for BCST that may allow for more frequent screening if one's $\mathrm{BC}$ risk level is higher than that of the general population. The econometric exercise revealed that seven individual factors were found significantly associated with both interest in and WTP for BCST: age, household income, marital status, family history, locus of control (powerful others), perceived health status and numeracy, while five factors were found significantly associated only with interest in BCST: optimism, monitoring, locus of control (chance), anxiety and perceived risk. A quick comparison of our study results with the ones of the literature is available in online supplementary appendix 1 .

The results of this study have limitations that inform the interpretation of its results and suggest further research. First, our findings might be considered as representative of French-speaking women aged between 35 and 69 years living in Québec (Canada), but should be cautiously extrapolated to other similar or neighbouring populations. Previous studies called attention to the great variability regarding interest level and WTP estimates across populations studied for genetic testing in general. ${ }^{92}$ Second, our response rate may seem low $(43 \%)$, but several prior studies on interest in and WTP for genetic testing obtained comparable response rates. ${ }^{556}$ Third, self-reported data like those used in this study are subject to a social desirability bias. Fourth, as done in previous studies, ${ }^{27} 343557$ a hypothetical scenario was used in this study. Then, reported results on the degree of interest in and WTP for BCST should not be taken as an objective uptake measure of testing, but as a measure of intention. ${ }^{92738}$ Other studies have also demonstrated that revealed measures of WTP overestimate the sum paid out-of-pocket in a realistic situation. ${ }^{27} 3458$ Fifth, different measures of WTP or elicitation techniques to value BCST in the general population in Québec should be used to confirm our findings. Indeed, the literature revealed discrepancies between studies of WTP estimates according to measures and methods employed for similar tests. ${ }^{32}$ Moreover, we used only one item to measure WTP on an ordered scale. This is among the several ways used by authors to measure WTP ${ }^{33}$ even though many studies opted for double or multiple biding items. ${ }^{59}$ Furthermore, it has been demonstrated that each of the measurement methods has its strengths and limitations, but above all, the level of accuracy gained by the econometric model used afterward is negligible in the case of sample sizes like ours $(\mathrm{n}=1031) .{ }^{59}$ Finally, as this paper only focused on individual factors, future studies should investigate other potential factors associated with interest in and WTP for BCST, like those at the organisational, social or environmental level and should more explicitly ground the explanatory variables in theoretical frameworks. Other aspects could contribute to the choice of being genetically tested, and this may vary by type of genetic test and the purpose of its use. ${ }^{92}$ This also has implications in terms of results' interpretation. Significance and effects of individual factors discussed above are subject to change if other contributing factors to the overall predictive power would be added in the respective equations of INTER and WTP modelling. ${ }^{41}$ 


\section{Potential implications}

The findings of this study first provide a proxy for the readiness of women of the general population of Québec to get genetically tested for BC susceptibility and the amount they expect to be acceptable to pay for such services in private settings, given the formulation of the scenario. While we did not assess various payments vehicles, our results may provide insights (1) on the willingness of the general population to make accessible BCST to more women in the context of the current publicly funded system; (2) on their degree of openness towards a new copayment method for such a test or (3) on the setting of insurance copayments, if any, in some situations. $^{22} 32$ As the results show, a majority of the women were at least somewhat interested in BCST ( 90\%), and more than half were willing to pay a certain amount of money for such a test. Indeed, nearly $35 \%$ of the women of our sample would pay up to $\$ 100,15 \%$ up to $\$ 250$ and $7 \%$ more than $\$ 250$. However, a great proportion of them was not willing to pay (24\%) or did not provide information on the survey item assessing their WTP for BCST ( $18 \%$ of missing data, which includes $9 \%$ of respondents 'Not interested at all' in BCST). Overall, this suggests that the women of Québec have mitigated enthusiasm towards BCST if they have to pay for it, which is consistent with another study led in the Canadian context. ${ }^{37}$ While it may reflect some important values of Canadian citizens that are embodied in the Medicare system, ${ }^{30}$ studies led in private healthcare systems reported similar findings. ${ }^{35} 56$

Second, the results suggest that many psychosocial factors are associated with women's interest in and WTP for BCST. Indeed, in line with the findings of several prior studies on cancer susceptibility testing, ${ }^{35} 60-63$ our results reveal that the higher the women's BC risk perceptions are, the higher their level of interest in BCST is. It is worth mentioning, however, that women's interest in BCST should be analysed in light of another important finding: women greatly overestimated both their personal lifetime risk of developing $\mathrm{BC}$ and that of women of the general population. Similar results were also found in other populations. ${ }^{64-66}$ This overestimation may be due to a lack of knowledge, a low level of numeracy or otherwise unrealistic worries about BC. ${ }^{64-66}$ In addition, as reported by other studies, ${ }^{2756}$ more anxious, less optimistic women and those with poor numeracy skills are more interested in BCST and thus, will probably more extensively use such services. This may suggest that some moderating psychosocial variables might influence the women's decision process to get tested or not. Moreover, it could result in a biased level of interest in and WTP for BCST.

Previous studies have also reported an association between perceived control or risk tolerance and interest in and WTP for cancer susceptibility testing. ${ }^{34} 3567$ Our results support this finding and indicate that one of the most impactful factors on women's interest and WTP is the external health locus of control-powerful others. It implies that a woman who believes that others she considers as experts are largely responsible for her health is more interested in and willing to pay for BCST. As underlined in studies on BC screening, ${ }^{68}$ this result suggests that healthcare providers' recommendations, public health or for-profit organisations' communication campaigns or marketing strategies might have an impact on some women's interest in and WTP for BCST. Beyond that, private companies' DTC advertising efforts may take advantage of actual consumers' emotional concerns or knowledge deficit in genetics. ${ }^{25} 56$ These companies should thus be fully encouraged to incorporate adapted modes of communication and provide personalised risk counselling to consumers, instead of their current approach of 'one-size-fits-all' ${ }^{25}$

These facts lead, as others proposed, ${ }^{92735}$ to reiterate the necessity of putting a stronger emphasis on popular education and of developing educational material towards genetics and the notion of risk to ensure that the choice of getting tested for BC susceptibility is made following an informed decision-making process and based on more objective and realistic risk perceptions of BC. As a starting point, we suggest that some lessons learnt from public health and charity organisation messages and decision aids (eg, information from leaflet or web page, communication campaigns and other health promotion strategies) about cancer screening ${ }^{68}{ }^{69}$ may serve as a building block for the dissemination of BCST information among the general population. The literature on $\mathrm{BC}$ risk communication may also provide important cues on the most comprehensive ways genetic risk should be transmitted to women of the general population. ${ }^{70}$ Interventions improving knowledge and awareness, as well as fostering objective BC risk evaluation, have the potential to improve ethical and informed decision-making, ${ }^{68} 69$ but may also slightly decrease interest in and WTP for BCST. ${ }^{9356}$

Third, the findings of this study may help health organisations, either private or public, to better define the range of service offerings or to adjust service delivery modalities to public or consumers' preferences and needs. ${ }^{35} 36$ For instance, following results discussed previously on perceived risk, numeracy, anxiety or optimism, it seems that reassurance, support and education as provided in highly specialised services of genetic counselling are important elements to be adapted for public healthcare settings - such as in the case of the implementation of a BC risk stratification programme-and to be provided by private companies selling BCST directly to consumer in order to minimise drawbacks for women (eg, anxiety, miscomprehensions and so on)..$^{253556}$

Finally, study results related to some medical and demographic factors could provide insightful paths of action for developing strategies targeting specific subgroups of women in the population. For instance, women with a BC family history are more interested in and willing to pay for BCST. Several studies have reported similar findings. ${ }^{9} 3261627273$ They are also at greater risk of BC. ${ }^{74}$ Given their BC family history and their experience with this disease, some of them may be more aware of their increased BC risk. In turn, they may attribute more value 
and get more benefits from such testing than those without family history. Improving BCST access to those women, as other Canadian provinces did by adding public healthcare facilities, might be relevant. It could help to ensure that their interest and willingness to take the test is based on an informed decision instead of the results of biased self-(over) estimations of $\mathrm{BC}$ risk.

Moreover, paying more attention to young women (35-49 years old) in clinical encounters could be a winning strategy. It might contribute to the demystification of the notion of risk and the genetic component of $\mathrm{BC}$ into the next generation of women who will be likely invited into $\mathrm{BC}$ screening or stratification programmes. Furthermore, familial and genetic BC are often developed at a younger age than the sporadic form of $\mathrm{BC} .{ }^{75}$ So, this could lead to recommendations of early risk-management strategies for young women at greater risk of BC, who are less interested in and attribute less value to BCST, in taking into consideration their specificities and potential needs (eg, family-planning decisions) ${ }^{76} 77$

In addition, the study's results indicate that interest in and WTP for BCST increased with income. Even if this is in line with the budget constraint function of the economic theory ${ }^{35}$ and that previous studies pointed out similar findings, ${ }^{22} 3235$ inconsistent results are reported by a recent systematic review on interest in genetic testing. ${ }^{9}$ Likewise, some authors found mixed results regarding its association with the socioeconomic status. ${ }^{356061}$ As this concept reflects more broadly family or household resources, including education, employment, goods and revenues, one hypothesis may be that some confounding or moderating variables are involved in the decision-making process of women opting or not for BCST. Nevertheless, our results suggest that interventions designed for women from lower-resourced neighbourhoods or targeting physicians with a large panel of women with low income could prevent some inequalities in the uptake of BCST (eg, health or life insurance and employment discrimination, limited access to health services given the cost (if the test is pay-out-of-pocket or partially reimbursed by private insurance) or in the way the risk is assessed, ie, the risk factors considered, notably age, ethnicity and family history). ${ }^{7879}$

\section{CONCLUSION}

This study disentangles common and specific individual determinants of interest in and WTP for BCST among women of the general population of Québec (Canada). It also presents insights for developing inclusive and specific strategies that could support women's informed decision-making towards BCST and the range of service offerings by health organisations with regard to this test. For managers and decision-makers involved in $\mathrm{BC}$ prevention, thinking to adjust or to extend $\mathrm{BC}$ genetic services and desiring to adapt them to public preferences and needs, this study highlights two ways of proceeding that could be profitable from a social and economic point of view. The first is to develop interventions targeting the whole population, such as health promotion campaigns, by focusing on the psychosocial factors, given the number of significant factors explaining interest in and WTP for BCST. The second is to tailor interventions to particular subpopulations by considering the most impactful factors associated with interest in and WTP for BCST, such as family history backgrounds or strata of household income.

\section{Author affiliations}

${ }^{1}$ Department of Management, Université Laval, Québec, QC, Canada

${ }^{2}$ Centre des maladies du sein Deschênes-Fabia, Centre de recherche du CHU de Québec-Université Laval, Hôpital du Saint-Sacrement, Québec, QC, Canada ${ }^{3}$ Faculty of Medicine, Centre de recherche du CHU de Québec-Université Laval, Québec, QC, Canada

${ }^{4}$ Faculty of Pharmacy, Centre de recherche du CHU de Québec-Université Laval, Hôpital du Saint-Sacrement, Québec, QC, Canada

Acknowledgements The authors want to thank the reviewers for their insightful comments and suggestions on this manuscript.

Contributors All authors were responsible for the project design (led by JS and $M D)$. $M D$ and $K B$ were in charge of the survey development and the data collection. $\mathrm{JB}-\mathrm{B}$ and NA made the data analysis and drafted the preliminary version of the manuscript. All authors contributed to results' interpretation, commented on drafts and agreed on the final version of this article.

Funding This research was supported the Canadian Institutes of Health Research as a part of the CIHR Team in Familial Risks of Breast Cancer Grant (CRN-87521), and the PERSPECTIVE project, funded by The Government of Canada through Genome Canada and the Canadian Institutes of Health Research (GPH-129344), the Ministère de l'Économie, de la Science et de l'Innovation du Québec through Genome Québec, and the Québec Breast Cancer Foundation.

\section{Competing interests None declared.}

Patient consent Detail has been removed from this case description/these case descriptions to ensure anonymity. The editors and reviewers have seen the detailed information available and are satisfied that the information backs up the case the authors are making.

Ethics approval This study was approved by the Comité d'éthique et de la recherche du CHU de Québec-Université Laval (\#2012-1584/2012-HSS-300-05).

Provenance and peer review Not commissioned; externally peer reviewed.

Data sharing statement № additional data are available.

Open Access This is an Open Access article distributed in accordance with the Creative Commons Attribution Non Commercial (CC BY-NC 4.0) license, which permits others to distribute, remix, adapt, build upon this work non-commercially, and license their derivative works on different terms, provided the original work is properly cited and the use is non-commercial. See: http://creativecommons.org/ licenses/by-nc/4.0/

(c) Article author(s) (or their employer(s) unless otherwise stated in the text of the article) 2018. All rights reserved. No commercial use is permitted unless otherwise expressly granted.

\section{REFERENCES}

1. Khoury MJ, Coates RJ, Fennell ML, et al. Multilevel research and the challenges of implementing genomic medicine. J Natl Cancer Inst Monogr 2012;2012:112-20.

2. Health Leaders Media - a division of HCPro Inc. In collaboration with price water house cooper. The impact of personalized medicine today Massachusetts, United-States2010. http://www. healthleadersmedia.com/breakthroughs

3. Welch BM, Kawamoto K. Clinical decision support for genetically guided personalized medicine: a systematic review. J Am Med Inform Assoc 2013;20:388-400.

4. Diamandis M, White NM, Yousef GM. Personalized medicine: marking a new epoch in cancer patient management. Mol Cancer Res 2010;8:1175-87. 
5. Gouvernement du Canada - Canadian Institutes of Health Research. Personalized medicine 2015. http://www.cihr-irsc.gc.ca/e/43627.html

6. Foulkes WD, Knoppers BM, Turnbull C. Population genetic testing for cancer susceptibility: founder mutations to genomes. Nat Rev Clin Oncol 2016;13:41-54.

7. Dent T, Jbilou J, Rafi I, et al. Stratified cancer screening: the practicalities of implementation. Public Health Genomics 2013;16:94-9.

8. Ginsburg GS, Willard HF. Genomic and personalized medicine: foundations and applications. Trans/ Res 2009;154:277-87.

9. Sweeny K, Ghane A, Legg AM, et al. Predictors of genetic testing decisions: a systematic review and critique of the literature. J Genet Couns 2014;23:263-88.

10. Burton $\mathrm{H}$, Jackson $\mathrm{C}$, Abubakar I. The impact of genomics on public health practice. Br Med Bull 2014;112:37-46.

11. Chowdhury S, Dent T, Pashayan N, et al. Incorporating genomics into breast and prostate cancer screening: assessing the implications. Genet Med 2013;15:423-32.

12. Evans DG, Donnelly LS, Harkness EF, et al. Breast cancer risk feedback to women in the UK NHS breast screening population. Br J Cancer 2016;114:1045-52.

13. Evans DG, Howell A. Can the breast screening appointment be used to provide risk assessment and prevention advice? Breast Cancer Res 2015;17:841.

14. Couch FJ, Nathanson KL, Offit K. Two decades after BRCA: setting paradigms in personalized cancer care and prevention. Science 2014;343:1466-70.

15. Howe R, Miron-Shatz T, Hanoch Y, et al. Personalized medicine through SNP testing for breast cancer risk: clinical implementation. $J$ Genet Couns 2015;24:744-51.

16. Easton DF, Pharoah PD, Antoniou AC, et al. Gene-panel sequencing and the prediction of breast-cancer risk. N Engl J Med 2015;372:2243-57.

17. Michailidou K, Lindström S, Dennis J, et al. Association analysis identifies 65 new breast cancer risk loci. Nature 2017;551:92-4

18. Amara N, Blouin-Bougie J, Jbilou J, et al. The knowledge value-chain of genetic counseling for breast cancer: an empirical assessment of prediction and communication processes. Fam Cancer 2016:15:1-17.

19. O'Daniel JM. The prospect of genome-guided preventive medicine: a need and opportunity for genetic counselors. J Genet Couns 2010;19:315-27.

20. Howell A, Astley S, Warwick J, et al. Prevention of breast cancer in the context of a national breast screening programme. J Intern Med 2012;271:321-30.

21. Onega T, Beaber EF, Sprague BL, et al. Breast cancer screening in an era of personalized regimens: a conceptual model and National Cancer Institute initiative for risk-based and preference-based approaches at a population level. Cancer 2014;120:2955-64.

22. Kilambi V, Johnson FR, González JM, et al. Valuations of genetic test information for treatable conditions: the case of colorectal cancer screening. Value Health 2014;17:838-45.

23. Narod SA. BRCA mutations in the management of breast cancer: the state of the art. Nat Rev Clin Oncol 2010;7:702-7.

24. Goldsmith L, Jackson L, O'Connor A, et al. Direct-to-consumer genomic testing: systematic review of the literature on user perspectives. Eur J Hum Genet 2012;20:811-6.

25. Bellcross CA, Page PZ, Meaney-Delman D. Direct-to-consumer personal genome testing and cancer risk prediction. Cancer $J$ 2012;18:293-302.

26. Zimmern RL, Khoury MJ. The impact of genomics on public health practice: the case for change. Public Health Genomics 2012;15:118-24.

27. Graves KD, Peshkin BN, Luta G, et al. Interest in genetic testing for modest changes in breast cancer risk: implications for SNP testing. Public Health Genomics 2011;14:178-89.

28. Kristoffersson U, Schmidtke J, Cassiman J. Quality issues in clinical genetic services: Springer, 2010.

29. Gouvernement du Québec. Québec Breast Cancer Screening Program 2017. http://sante.gouv.qc.ca/en/programmes-et-mesuresdaide/programme-quebecois-de-depistage-du-cancer-du-seinpqdcs/ (accessed 12 Nov 2017).

30. Loeppky R. Canada, health and historical political economy. Journal of Australian Political Economy 2014;73:172-99.

31. Ries N, Einsiedel E. Test génétiques offerts directement aux consommateurs via Internet - Enjeux et options stratégiques. In: Mémoires stratégiques. Génome Canada: Répercussions sociétales et politiques publiques, 2010:9.

32. Lin PJ, Cangelosi MJ, Lee DW, et al. Willingness to pay for diagnostic technologies: a review of the contingent valuation literature. Value Health 2013;16:797-805.
33. Kopits IM, Chen C, Roberts JS, et al. Willingness to pay for genetic testing for Alzheimer's disease: a measure of personal utility. Genet Test Mol Biomarkers 2011;15:871-5.

34. Neumann PJ, Cohen JT, Hammitt JK, et al. Willingness-to-pay for predictive tests with no immediate treatment implications: a survey of US residents. Health Econ 2012;21:238-51.

35. Bosompra K, Ashikaga T, Flynn BS, et al. Psychosocial factors associated with the public's willingness to pay for genetic testing for cancer risk: a structural equations model. Health Educ Res 2001:16:157-72.

36. Matro JM, Ruth KJ, Wong YN, et al. Cost sharing and hereditary cancer risk: predictors of willingness-to-pay for genetic testing. $J$ Genet Couns 2014;23:1002-11.

37. Ries NM, Hyde-Lay R, Caulfield T. Willingness to pay for genetic testing: a study of attitudes in a Canadian population. Public Health Genomics 2010;13:292-300

38. Lacour RA, Daniels MS, Westin SN, et al. What women with ovarian cancer think and know about genetic testing. Gynecol Oncol 2008;111:132-6.

39. Saha A, Capps O, Byrne PJ. Calculating marginal effects in dichotomous - continuous models. Appl Econ Lett 1997;4:181-5.

40. Hanmer MJ, Ozan Kalkan K. Behind the curve: clarifying the best approach to calculating predicted probabilities and marginal effects from limited dependent variable models. Am J Pol Sci 2013:57:263-77.

41. Mood C. Logistic Regression: why we cannot do what we think we can do, and what we can do about it. Eur Sociol Rev 2010;26:67-82.

42. Statistics Canada. Enquête sur la santé dans les collectivités canadiennes (ESSC), 2010:417.

43. Gail MH, Brinton LA, Byar DP, et al. Projecting individualized probabilities of developing breast cancer for white females who are being examined annually. J Natl Cancer Inst 1989;81:1879-86.

44. Field A. Discovering statistics using IBM SPSS statistics: Sage, 2013

45. Faul F, Erdfelder E, Buchner A, et al. Statistical power analyses using G*Power 3.1: tests for correlation and regression analyses. Behav Res Methods 2009;41:1149-60.

46. Portney LG, Watkins MP. Foundations of clinical research: applications to practice. 3rd edn. Philadelphia, USA: FA Davis Co, 2015.

47. Aldrich $\mathrm{JH}$, Nelson FD, probability L. Linear probability, logit, and probit models: Sage, 1984

48. Greene WH, Hensher DA. Modeling ordered choices: a primer. 1st edn: Cambridge University Press, 2010.

49. Fullerton AS. A conceptual framework for ordered logistic regression models. Sociol Methods Res 2009;38:306-47.

50. Bushway S, Johnson BD, Slocum LA. Is the magic still there? The use of the heckman two-step correction for selection bias in criminology. J Quant Criminol 2007;23:151-78.

51. Dubin JA, Rivers D. Selection bias in linear regression, logit and probit models. Sociol Methods Res 1989;18:360-90.

52. Amara N, Ouimet M, Landry RÉjean. New evidence on instrumental, conceptual, and symbolic utilization of university research in government agencies. Sci Commun 2004;26:75-106.

53. SPSS Inc. SPSS for Windows. Version 13.0. Chicago, USA: SPSS Inc. 2004.

54. Greene WH. LIMDEP: Version 8.0: Econometric Modeling Guide: Econometric Software, 2002.

55. Neumann PJ, Hammitt JK, Mueller C, et al. Public attitudes about genetic testing for Alzheimer's disease. Health Aff 2001;20:252-64

56. Miron-Shatz T, Hanoch Y, Doniger GM, et al. Subjective but not objective numeracy influences willingness to pay for BRCA $1 / 2$ genetic testing. Judgment and Decision Making 2014:9:152-8.

57. Michael F, Drummond MJS, Claxton K, et al. Methods for the economic evaluation of health care programmes. 4th edn, 2015.

58. Cookson R. Willingness to pay methods in health care: a sceptical view. Health Econ 2003;12:891-4.

59. Calia P, Strazzera E. Bias and efficiency of single versus double bound models for contingent valuation studies: a Monte Carlo analysis. Appl Econ 2000;32:1329-36.

60. Bosompra K, Flynn BS, Ashikaga T, et al. Likelihood of undergoing genetic testing for cancer risk: a population-based study. Prev Med 2000;30:155-66.

61. Bunn JY, Bosompra K, Ashikaga T, et al. Factors influencing intention to obtain a genetic test for colon cancer risk: a population-based study. Prev Med 2002;34:567-77.

62. Kinney AY, Croyle RT, Dudley WN, et al. Knowledge, attitudes, and interest in breast-ovarian cancer gene testing: a survey of a large African-American kindred with a BRCA1 mutation. Prev Med 2001;33:543-51.

63. Reitz F, Barth J, Bengel J. Predictive value of breast cancer cognitions and attitudes toward genetic testing on women's 
interest in genetic testing for breast cancer risk. Psychosoc Med 2004; 1:Doc03.

64. Rutherford EJ, Kelly J, Lehane EA, et al. Health literacy and the perception of risk in a breast cancer family history clinic. Surgeon 2016.

65. MacTiernan A, Fritschi L, Slevin T, et al. Public perceptions of cancer risk factors: a Western Australian study. Health Promot J Austr 2014;25:90-6.

66. Fehniger J, Livaudais-Toman J, Karliner L, et al. Perceived versus objective breast cancer risk in diverse women. $J$ Womens Health 2014;23:420-7.

67. Nordin K, Björk J, Berglund G. Factors influencing intention to obtain a genetic test for a hereditary disease in an affected group and in the general public. Prev Med 2004;39:1107-14.

68. Hersch JK, Nickel BL, Ghanouni A, et al. Improving communication about cancer screening: moving towards informed decision making. Public Health Res Pract 2017;27.

69. Vrinten C, McGregor LM, Heinrich M, et al. What do people fear about cancer? A systematic review and meta-synthesis of cancer fears in the general population. Psychooncology 2017;26:1070-9.

70. Dorval M, Bouchard K, Chiquette J, et al. A focus group study on breast cancer risk presentation: one format does not fit all. Eur $\mathrm{J}$ Hum Genet 2013;21:719-24.

71. Julian-Reynier C, Welkenhuysen M, Hagoel L, et al. Risk communication strategies: state of the art and effectiveness in the context of cancer genetic services. Eur J Hum Genet 2003;11:725-36.

72. Bottorff JL, Ratner PA, Balneaves LG, et al. Women's interest in genetic testing for breast cancer risk: the influence of sociodemographics and knowledge. Cancer Epidemiol Biomarkers Prev 2002;11:89-95.
73. Braithwaite D, Sutton S, Steggles N. Intention to participate in predictive genetic testing for hereditary cancer: the role of attitude toward uncertainty. Psychol Health 2002;17:761-72.

74. National Cancer Institute $(\mathrm{NCl})$ and the National Surgical Adjuvant Breast and Bowel Project (NSABP). The breast cancer risk assessment tool 3.0: U.S. Department of Health and Human Services, 2011.

75. Easton DF, Ford D, Bishop DT. Breast and ovarian cancer incidence in BRCA1-mutation carriers. Breast Cancer Linkage Consortium. Am J Hum Genet 1995;56:265.

76. Evans C, Hamilton RJ, Tercyak KP, et al. Understanding the needs of young women regarding breast cancer risk assessment and genetic testing: convergence and divergence among patientcounselor perceptions and the promise of peer support. Healthcare 2016;4:35.

77. Ahmad S, Fergus K, McCarthy M. Psychosocial issues experienced by young women with breast cancer: the minority group with the majority of need. Curr Opin Support Palliat Care 2015;9:271-8.

78. Gouvernement du Québec - Commission de l'éthique en science et en technologie. Soins de santé personnalisés: document de consultation Québec. 44, 2012.

79. McClellan KA, Avard D, Simard J, et al. Personalized medicine and access to health care: potential for inequitable access? Eur J Hum Genet 2013;21:143-7.

80. Gail MH. Twenty-five years of breast cancer risk models and their applications. J Natl Cancer Inst 2015;107:djv042.

81. Fisher RA. Statistical methods and scientific inference, 1956.

82. Lipsey MW. Design sensitivity: statistical power for experimental research: Sage, 1990.

83. Noymer A. Alpha, significance level of test. Encyclopedia of survey research methods. 18, 2008. 